\title{
UMA MUDANÇA EM ANDAMENTO: A TROCA DE "CASA" DA TORCIDA DO CLUBE NÁUTICO CAPIBARIBE SOB O OLHAR DA CASA E DA RUA DE ROBERTO DAMATTA
}

\author{
${ }^{1}$ Bruno Rafael Torres Ferreira \\ 2 André Luiz Maranhão de Souza Leão
}

\begin{abstract}
RESUMO
Um dos novos estádios construídos para a Copa do Mundo FIFA Brasil 2014, a Arena Pernambuco converteu-se em uma parceria entre o consórcio responsável pela gestão da arena e o Clube Náutico Capibaribe. A associação promoveu uma situação nova para a torcida alvirrubra: a mudança do Estádio dos Aflitos, que congrega muito da história do clube, para a Arena Pernambuco, um novo modelo de estádio. Assim, o objetivo do presente trabalho é compreender como a torcida do Náutico significa esses espaços sociais. Para tal, realizamos uma etnografia da comunicação, baseada em registros observacionais de interações entre torcedores, realizadas em idas aos jogos do Náutico entre abril e dezembro de 2013. Usamos a perspectiva teórica de Roberto DaMatta como lente para interpretação. Nossos achados evidenciam dois pontos de vista no processo de significação dos espaços sociais em questão: um ligado a valores específicos da comunidade, resultantes das relações ou laços construídos ao longo do tempo, e outro fundamentado em regras e valores de uma ordem social mais ampla, vigente na atualidade. Tais aspectos contribuem para uma reflexão acerca do futebol como elemento significativo na dinâmica entre espaços e práticas sociais, bem como o modo como esta dinâmica reflete também a dimensão econômica desse esporte.
\end{abstract}

Palavras-chave: Casa e Rua. Torcida de futebol. Estádio dos Aflitos. Arena Pernambuco. Clube Náutico Capibaribe.

\section{A CHANGE IN PROGRESS: THE CLUBE NÁUTICO CAPIBARIBE'S FANS “HOME" EXCHANGE UNDER ROBERTO DAMATTA'S HOUSE AND STREET VIEW}

\begin{abstract}
One of the new arenas built for the FIFA World Cup Brazil 2014, Arena Pernambuco, became a partnership between the consortium responsible for its management and the Clube Náutico Capibaribe. The association promoted a new situation for the red-white fans: moving from Estádio dos Aflitos, which brought much of the club's history, to the Arena Pernambuco, a new stadium model. Thus, the objective of this work is to understand how Náutico's fans signified those social spaces. Thus, we conducted an ethnography of communication, based on observational records of interactions between fans held on visits to Náutico matches between April and December 2013. We also used Roberto DaMatta theoretical perspective as lens for interpretation. Our findings evidenced two points of view in the process of signification of such social spaces: one linked to particular values of the community, resulting from relations and ties constructed over time, and other based on rules and values of a wider social order, current nowadays. These aspects contribute to think of soccer as a significant element in the dynamics between social spaces and practices and how this dynamic also reflects the economic dimension of that sport.
\end{abstract}

Keywords: House and Street. Soccer fans. Estádio dos Aflitos. Arena Pernambuco. Clube Náutico Capibaribe.

\footnotetext{
${ }^{1}$ Doutorando pelo Programa de Pós-graduação em Administração pela Universidade Federal de Pernambuco - UFPE, Brasil.

E-mail: brunortferreira@gmail.com

${ }^{2}$ Doutor em Administração pela Universidade Federal de Pernambuco - UFPE, Brasil.

Professor adjunto do Departamento de Ciências Administrativas (DCA/UFPE).

E-mail: aleao21@hotmail.com

A realização deste trabalho só foi possível graças ao apoio do Conselho Nacional de Desenvolvimento Científico e Tecnológico (CNPq).
} 


\section{UN CAMBIO EN MARCHA: EL INTERCAMBIO DE “CASA" DE LOS AFICIONADOS POR EL CLUBE NÁUTICO CAPIBARIBE DESDE EL ÓPTICA DE LA CASA E DE LA CALLE DE ROBERTO DAMATTA}

\section{RESUMO}

Uno de los nuevos estadios construidos para la Copa del Mundo FIFA Brasil 2014, la Arena Pernambuco se convirtió en una asociación entre el consorcio responsable de la gestión de la arena y el Clube Náutico Capibaribe. La asociación ha promovido una nueva situación para los aficionados alvirrubros: cambiar el Estadio de los Afligidos, que reúne a gran parte de la historia del club, para la Arena Pernambuco, un nuevo modelo de estadio. Tan, el objetivo de este trabajo es entender cómo los aficionados del Náutico significan estos espacios sociales. Con este fin, se realizó una etnografía de la comunicación, sobre la base de registros de observación de las interacciones entre los aficionados celebradas en las visitas a los juegos de Náutico, entre abril y diciembre de 2013. Utilizamos la perspectiva teórica de Roberto DaMatta como lente para la interpretación. Nuestros hallazgos muestran dos puntos de vistas en el proceso de significación de los espacios sociales en cuestión: una vinculada a los valores específicos de la comunidad, como resultado de las relaciones o lazos construidos con el tiempo, y el otro basado en normas y valores de una orden social más amplia, actualmente prevaleciente. Estos aspectos contribuyen a una reflexión sobre el fútbol como un elemento significativo en la dinámica entre los espacios y las prácticas sociales y cómo esta dinámica también refleja la dimensión económica del deporte.

Palavras-chave: Casa e Rua. Torcida de futebol. Estádio dos Aflitos. Arena Pernambuco. Clube Náutico Capibaribe. 


\section{INTRODUÇÃO}

Com a Copa do Mundo da Fédération Internationale de Football Association (FIFA), as 12 cidades-sede receberam investimentos públicos e privados em obras de mobilidade, segurança, telecomunicações e turismo. Destas obras, a reforma dos antigos e a construção de novos estádios buscaram atender as especificações da FIFA acerca da segurança e o conforto de atletas, espectadores e profissionais ligados direta e indiretamente ao evento (Andrade \& Braga, 2014; Nascimento \& Barreto, 2013). A reformulação dos estádios para a Copa do Mundo ilustra a chegada do conceito de arena que busca trazer, por um lado, uma nova forma de ver partidas de futebol para os torcedores e, por outro, novas possibilidades de negócios para clubes e empresas que estão por trás dos novos empreendimentos (Souto \& Torres, 2010; Fernandes, 2013).

Entre as novas arenas construídas para o megaevento, a Arena Pernambuco foi produto da parceria entre o governo estadual e o Consórcio Arena Pernambuco, financiada pelo Banco Nacional de Desenvolvimento (BNDES) e pelo Governo do Estado (Nascimento, 2014; Seixas \& Lopes, 2012). Observando a situação do futebol pernambucano dentro do contexto nacional, a nova arena tem a possibilidade de gerar receitas, tendo em vista que os três maiores clubes pernambucanos (Sport, Santa Cruz e Náutico) estão entre os 20 clubes com o maior número de torcedores no Brasil (Pluri Stochos, 2013).

A parceria entre a Arena Pernambuco e o Clube Náutico Capibaribe nasceu neste contexto, em 2011, prevendo investimentos e parte das receitas para o clube alvirrubro (Wagner, 2011). Da mesma forma que esta parceria representa para o clube oportunidade de crescimento, temos também uma situação de mudança na qual a torcida alvirrubra se encontra: de um lado está o Estádio dos Aflitos, o antigo estádio, que compreende significados importantes para os alvirrubros; do outro, a Arena Pernambuco, um novo modelo de estádio e reflexo de um novo cenário para $o$ futebol trazido pela organização da Copa do Mundo.

Assumindo que a realidade seja socialmente construída (Berger \& Luckmann, 2006), adotamos a concepção de que coisas, práticas e fenômenos têm seus significados constituídos (e reconstituídos) nas atividades e interações de indivíduos de um grupo social. Diante disto, o objetivo deste estudo foi compreender os significados de tais espaços para a torcida alvirrubra pernambucana. Tal proposta visa ao entendimento de como esta comunidade dá sentido aos dois estádios no processo de mudança. Para tal, fizemos uso da perspectiva teórica de Roberto DaMatta, que nos oferece, em suas categorias sociológicas da Casa e da Rua, esferas de significados com particularidades que ilustram características da sociedade brasileira. Assim, para nortear os rumos desta pesquisa, elaboramos a seguinte pergunta investigativa: como a torcida do Clube Náutico Capibaribe significa o Estádio dos Aflitos e a Arena Pernambuco?

Justificamos a realização desta pesquisa pela possibilidade de exploração deste fenômeno marcadamente global, uma vez que segue tendências mundiais sobre a força de se fruir o futebol — pelo olhar de uma linha de pensamento brasileiro, no que diz respeito ao modo de ver e entender o mundo (Ianni, 2002), acerca do futebol, prática tão relacionada à própria cultura brasileira (e.g. Caldas, 1997; DaMatta, 2006; Kaz \& Silva, 2013). Neste sentido, segue a linha de outros estudos que se debruçam sobre o vínculo entre torcedores e os estádios de futebol, como o de Barreto e Nascimento (2011) - que corrobora a ideia da existência de um vínculo entre a torcida e o estádio do seu time, carregado de significados que passam pela alegria de uma vitória ou de um título, pela fúria e tristeza das derrotas, bem como pelas relações entre os indivíduos que circulam naquele espaço - e o de Capraro (2004), que analisa a construção da identidade do torcedor do Atlético Paranaense a partir do papel da Arena da Baixada. A relação entre fatores socioculturais locais e seus reflexos em torno do futebol são alvos de estudos em outros países: por exemplo, Stone (2007) estuda o papel do futebol nas práticas cotidianas, ao observar o sentimento de pertencimento e de identificação que se constrói historicamente em comunidades a partir de práticas direta e indiretamente ligadas ao futebol; Merkel (2007) fez uma análise do impacto das mudanças sociais e culturais que o futebol alemão e nas práticas dos fãs do esporte no país passaram ao longo dos anos, e Cleland e Cashmore $(2014,2016)$ tratam da posição de torcedores britânicos acerca do racismo no futebol. Assim, a pesquisa localiza-se no campo da sociologia do futebol (vide Giulianotti, 2010), uma vez que o fenômeno aqui tratado e a lente teórica escolhida - assim como os demais autores e obras visitados e citados nesta pesquisa - trazem à tona aspectos da sociedade brasileira e das dimensões sociais do futebol construídas ao longo da história.

O trabalho está organizado em seções. Além desta introdução, descrevemos, na seção a seguir, os fundamentos teóricos que nortearam nossa interpretação, baseada na perspectiva da Casa e da Rua de Roberto DaMatta. Na terceira seção apresentamos como se deu o uso da etnografia da comunicação como procedimento que compreende a coleta e análise de dados, como também a constituição do corpus da pesquisa. A descrição dos resultados foi dividida em três seções, a partir de nossa interpretação da significação dos estádios: a primeira, relativa às nossas observações nos últimos jogos do Náutico mandados nos Aflitos antes da mudança para a Arena Pernambuco, quando já havia uma expectativa pela 
novidade; a segunda, imediatamente após a mudança, quando ainda havia um estranhamento em relação ao novo espaço; por fim, a terceira, apresenta o momento em que a nova arena já começava a ser reconhecida. Por fim, na última seção fazemos nossas

\section{As categorias sociológicas de Roberto DaMatta}

Apontado como um dos principais pensadores brasileiros a interpretar o futebol enquanto esporte e como importante fator na constituição da identidade brasileira (Giglio \& Spaggiari, 2010; Capraro, 2015), Roberto DaMatta ressalta a importância do aspecto social do futebol na sociedade brasileira (e. g. DaMatta, 1982; 2006) ao atribuir ao futebol uma "força integrativa" (2006. p. 164) que, em uma primeira dimensão, ilustra para a sociedade brasileira (usando o time de futebol como elemento) a capacidade de organização, trabalho coordenado e, como fruto desses, a possibilidade de vitória. Outro ponto importante neste cenário é o papel do torcedor, uma figura ativa que, no jogo e em sua coletividade (a torcida), "joga" com o time pelo qual torce - o " $122^{\circ}$ jogador", no jargão do mundo do futebol. E essa escolha do time pelo qual torcer é, para DaMatta (2006), um primeiro fator - externo à esfera familiar - no processo de construção de sua identidade: é o futebol como "primeira porta para o mundo público" (p. 162).

Visando entender a organização da realidade brasileira, DaMatta (1997) desenvolveu as categorias sociológicas da Casa e da Rua ${ }^{3}$. Elas são usadas como esferas para explicar como uma sociedade pensa e constrói seu quadro de códigos, seus valores, ideias e sistemas classificatórios. Tavolaro (2008) ressalta a importância da proposta de DaMatta, afirmando que "a noção de que a experiência brasileira contemporânea é não só diferente como também única quando comparada a outras sociedades ocidentais" (Tavoralo, 2008, p. 278).

Fazendo uma descrição inicial, podemos dizer que, do ponto de vista da Casa está o olhar pessoal, em que a emoção fala alto e é englobada ao espaço social, enquanto a Rua representa a voz da lei, mais rígida. Para DaMatta (1997, p.14)

[...] estas palavras não designam simplesmente espaços geográficos ou coisas físicas comensuráveis, mas, acima de tudo, entidades morais, esferas de ação social, províncias éticas dotadas de positividade, domínios culturais institucionalizados e, por causa disso, capazes de despertar emoções, reações, leis, orações, músicas e imagens esteticamente emolduradas e inspiradas.

Estas esferas podem ser hegemônicas, na considerações finais, nas quais descrevemos como dois pontos de vista se mostraram presentes no processo de significação das duas arenas, por parte da torcida alvirrubra.

prática, uma sobre a outra, dependo de qual categoria social um indivíduo, ou grupo, pertença. É o que o autor chama de englobamento: uma lógica poderá se sobressair, dependendo do contexto. Em um ambiente cuja esfera dominante é da Casa, adota-se uma postura moralizante, fundamentada em relações sociais e que envolve laços pessoais e lealdade. Já quando a esfera da Rua é tomada, leis e mecanismos impessoais reificam conceitos e relações.

Um ponto importante para entendermos a diferença entre essas concepções está na relação entre o individual e a coletividade. Nas sociedades onde o sistema capitalista é dominante, o indivíduo é mais importante do que o coletivo na sociedade, no que diz respeito à construção de leis e regras sociais. Nesta configuração, as leis e a ordem social protegem primeiramente o indivíduo, sendo a posição do grupo um estado de exceção. Temos, assim, a cidadania ou, melhor dizendo, as garantias dos direitos do cidadão (indivíduo) frente aos direitos de um grupo. Entretanto, nas sociedades mais tradicionais - como é o caso do Brasil, aponta o autor - os valores que envolvem a relação de grupos (por parentesco ou por um laço específico que une membros de um grupo social) são mais importantes do que o indivíduo em si. Esse aspecto representa a Casa, esfera na qual as relações pessoais garantem direitos a seus membros, chamados pelo autor de "supercidadãos", uma vez que têm seus direitos garantidos pelos laços de amizade ou de sangue e pela hierarquia social dentro de seu grupo social.

Do outro lado, na esfera da Rua, temos o ambiente ordenado pelas leis e pelos instrumentos de ordem social. Tais elementos garantem direitos e atribuem deveres aos indivíduos cidadãos $\mathrm{e}$, por serem de natureza impessoal, os laços pessoais sociais não são participantes da produção da ordem social. Assim, ao invés do "supercidadão" da Casa, a Rua revela um "Subcidadão":

Se no universo da casa sou um supercidadão, pois ali só tenho direitos e nenhum dever, no mundo da rua sou um subcidadão, já que as regras universais da cidadania sempre me definem por minhas determinações negativas: pelos meus deveres $\mathrm{e}$ obrigações, pela lógica do "não pode" e do "não deve". (DaMatta, 1997, p.84)

Podemos estabelecer uma relação de oposição entre as duas esferas de significação social: na Casa, temos a tradição, a segurança, as relações 
pessoais e familiares; do outro lado (ou, no lado de fora da Casa), na Rua, temos a impessoalidade, o perigo, as regras universais e o individualismo. Estas características de cada esfera fazem referência ao comportamento, aos valores, às regras sociais, ligadas ao espaço em que se desenrolam. Esta relação é dinâmica e relativa, na medida em que um espaço

\section{PROCEDIMENTOS METODOLÓGICOS}

A presente pesquisa se caracteriza como uma etnografia da comunicação, método que permite observar a estruturação e o papel do comportamento comunicativo na ordenação e na condução da vida social, a partir da interação entre sujeitos de mesma competência comunicativa (Saville-Troike, 2003). Tal abordagem está focada no entendimento do ambiente social por meio do processo dinâmico de interação e de interpretação de atores sociais em seu cotidiano (Gumperz, 2003).

Trata-se, por sua vez, de um tipo de análise de discurso de natureza funcional, uma vez que gira em torno da linguagem em uso (Gumperz, 1982c; Gumperz \& Hymes, 1986), tendo como critérios analíticos elementos de prosódia (Gumperz, 1982d), tais como acentuação, entoação, altura de voz e duração das elocuções; movimentos cinésicos (Birdwhistell, 1986), como gestos, movimentos pode ter as características de uma das esferas e, para tal delimitação, a presença da outra é fundamental. A um espaço que, geograficamente, tenda a ser entendido sob a ótica de uma dessas esferas, é possível se atribuir características da esfera oposta. É o que acontece quando um determinado espaço, típico da esfera da Rua, torna-se Casa, ou vice-versa.

dêiticos, expressões faciais e postura corporal; aspectos relativos à visão êmica dos interagentes pistas de contextualização (Gumperz, 1982a), alternância de código (GUMPERZ, 1982b) e conhecimento de mundo (Gumperz, 1982e) - e à definição do self social - elaboração da face (Goffman, 1967) e footing (Goffman, 1981). Tais elementos e critérios foram compilados no protocolo de análise de Leão e Mello (2007). A partir deste protocolo (Quadro 1), a análise do discurso foi realizada a partir da observação de elementos verbais e não-verbais das interações, analisando aspectos interacionais, que permite a inferência sobre elementos de perspectiva interna dos indivíduos que interagem; aspectos extralinguísticos, ligados a recursos corporais percebidas nas interações; e os paralinguísticos, ligados a dimensão fonética (Leão \& Mello, 2007).

\section{Quadro 1 - Protocolo de análise para etnografia da comunicação}

\begin{tabular}{|c|c|}
\hline \multicolumn{2}{|c|}{ Aspectos para linguísticos } \\
\hline Acentuação & $\begin{array}{l}\text { "Trata-se da intensidade dada a certos trechos silábicos e não necessariamente às sílabas } \\
\text { tônicas próprias de cada palavra. Isto quer dizer que não nos atemos se a acentuação } \\
\text { está correta ou não, do ponto de vista da norma culta". }\end{array}$ \\
\hline Altura de voz & $\begin{array}{l}\text { "A altura da voz refere-se à qualidade do som da fala relacionada à frequência de suas } \\
\text { vibrações (aguda, média, grave). Em nossa análise se caracteriza por ser mais baixa ou } \\
\text { mais alta em cada circunstância". }\end{array}$ \\
\hline Duração da elocução & $\begin{array}{l}\text { "A duração da elocução refere-se ao tempo de articulação do som da fala e varia, de } \\
\text { forma inversamente proporcional, de acordo com a velocidade de elocução. Toda } \\
\text { elocução, evidentemente, tem uma velocidade e, assim, uma duração, mas } \\
\text { consideramos apenas situações que contribuem na significação". }\end{array}$ \\
\hline Entoação & $\begin{array}{l}\text { "A entoação refere-se, fundamentalmente, às formas afirmativa, interrogativa e } \\
\text { exclamativa. Evidentemente, todas as elocuções têm entoações. Contudo, para efeito de } \\
\text { nossa análise, consideramos aquelas em que a força expressiva da entoação tenha } \\
\text { contribuído na significação". }\end{array}$ \\
\hline Tom & $\begin{array}{l}\text { "Tom é uma inflexão da voz que se refere à maneira de se expressar. Toda elocução é } \\
\text { acompanhada de tons de voz, evidentemente. Mais uma vez em nossas investigações } \\
\text { consideramos apenas os que contribuem na significação". }\end{array}$ \\
\hline Variações ortoépicas & $\begin{array}{l}\text { "As variações ortoépicas se referem àquelas dialetais e fonéticas. O primeiro tipo } \\
\text { refere-se ao impacto que diferentes sotaques têm sobre a pronúncia. A variação } \\
\text { fonética, por sua vez, trata-se dos chamados "barbarismos fonéticos", ou seja, palavras } \\
\text { soletradas erradamente. Em ambos os casos, não nos atemos a um sotaque padrão nem à } \\
\text { forma correta, do ponto de vista da norma culta, de se soletrar as palavras". }\end{array}$ \\
\hline
\end{tabular}

Aspectos extralinguísticos 


\begin{tabular}{|c|c|}
\hline Contato visual & $\begin{array}{l}\text { "O contato visual a que nos referimos se trata da comunicação que as pessoas } \\
\text { estabelecem entre si por meio do olhar, com o intuito de expressar alguma coisa ao } \\
\text { outro". }\end{array}$ \\
\hline Expressão facial & $\begin{array}{l}\text { "A noção de expressões faciais que assumimos se refere a variações no movimento } \\
\text { muscular da face que, voluntariamente ou não, expressem um sentimento, comumente } \\
\text { emotivo. Podem ser sorrisos - em suas diversas variedades (desde um "ar de riso" até } \\
\text { uma "gargalhada") - ou expressões com o rosto (tais como caretas, rubor da face } \\
\text { etc.)". }\end{array}$ \\
\hline Gestos & $\begin{array}{l}\text { "O que chamamos de gestos aqui se refere àqueles cujo uso já é consagrado numa dada } \\
\text { cultura, como, por exemplo, o polegar erguido com os demais dedos fechados para } \\
\text { indicar um sinal positivo". }\end{array}$ \\
\hline Movimento da cabeça & $\begin{array}{l}\text { "Os movimentos da cabeça que nos referimos aqui são posições ou movimentos } \\
\text { horizontais ou verticais que as pessoas fazem com a cabeça e que assuma um } \\
\text { significado para seu interagente". }\end{array}$ \\
\hline Movimento dêitico & $\begin{array}{l}\text { "Os movimentos dêiticos são tipos de gestos específicos. Diferentemente do que } \\
\text { chamamos de gestos, estes são demonstrativos de algo, como, por exemplo, apontar } \\
\text { para algo com o dedo ou inclinar a cabeça em direção de alguma coisa para evidenciá- } \\
\text { la". }\end{array}$ \\
\hline Postura & $\begin{array}{l}\text { "A postura corporal se refere à forma de se movimentar ou manter o corpo numa dada } \\
\text { posição, como forma de criar mais ou menos interesse ou intimidade, dentre outros, em } \\
\text { relação ao interagente". }\end{array}$ \\
\hline Movimentos corporais & $\begin{array}{l}\text { "Movimentos corporais são contatos físicos intrusivos - como empurrar, agarrar, } \\
\text { segurar etc. - como forma de impedir ou incentivar uma ação do interagente". }\end{array}$ \\
\hline Interações corporais & $\begin{array}{l}\text { "As interações corporais se referem ao contato pessoal afetuoso - por exemplo, um } \\
\text { aperto de mão, um toque, um abraço, dentre outros - que indica a proximidade afetiva } \\
\text { entre os interagentes". }\end{array}$ \\
\hline Distância corporal & $\begin{array}{l}\text { "A distância corporal se refere ao espaço em que duas ou mais pessoas estabelecem } \\
\text { entre si, indicando o grau de intimidade/formalidade entre os interagentes". }\end{array}$ \\
\hline \multicolumn{2}{|l|}{ Aspectos interacionais } \\
\hline Alternância de código & $\begin{array}{l}\text { "São passagens do uso de uma variedade linguística para outra, em que os participantes } \\
\text { de uma interação, de alguma forma, percebam como distintas. Nisto podemos incluir } \\
\text { mudanças de sotaque, de escolhas lexicais, de postura etc. Apesar de tais aspectos já } \\
\text { terem sido considerados em outras oportunidades, aqui aparecem como pontos de } \\
\text { articulação êmica, em que a alternância de um código para outro deve ser entendida } \\
\text { como uma demarcação de grupo cultural". }\end{array}$ \\
\hline Cenário & $\begin{array}{l}\text { "Por cenário temos o espaço delimitado do ambiente físico definido pelos participantes } \\
\text { como socialmente distintos de outros aspectos, no qual se desenrolam os eventos e as } \\
\text { atividades de fala, bem como o equipamento fixo de sinais ali presentes". }\end{array}$ \\
\hline Conhecimento de mundo & $\begin{array}{l}\text { "Conhecimento de mundo se refere a um conhecimento tácito, baseado em crenças, } \\
\text { hábitos e costumes compartilhados, teorias do senso comum, experiências vividas, fatos } \\
\text { e dados sociais, econômicos, políticos e de outras naturezas, que os interagentes têm } \\
\text { acerca dos mais variados aspectos e, por esperarem, conscientemente ou não, que os } \\
\text { seus interlocutores também tenham, o dão por certo". }\end{array}$ \\
\hline Contexto & $\begin{array}{l}\text { "Por contexto aqui assumimos qualquer conhecimento - de um fato ou situação, uma } \\
\text { informação, experiência etc. - alçado, direta ou indiretamente, voluntariamente ou não, } \\
\text { ao ambiente interacional". }\end{array}$ \\
\hline Face & $\begin{array}{l}\text { "Por face devemos entender o valor social positivo que um interagente almeja ter } \\
\text { reconhecido pelo outro por meio do que este presuma ser sua linha (conduta) durante } \\
\text { uma interação. Pode se mostrar como ameaça ou, por outro lado, salvação da face do } \\
\text { interagente ou de se próprio numa interação". }\end{array}$ \\
\hline Footing & "Se refere a uma mudança no alinhamento que alguém assume para si e para os outros. \\
\hline
\end{tabular}


Em outras palavras, como, durante uma interação, as pessoas mudam sua conduta de acordo com o desenrolar da mesma".

Fonte: Leão e Mello (2007)

O corpus de pesquisa foi construído pelo registro observacional de interações entre torcedores, nas quais fossem abordados assuntos relativos à mudança do mando de campo do time para a nova Arena. A depender da oportunidade, a observação foi feita de forma não-participante, com as interações sendo observadas de perto, mas sem interferência, ou participante, quando da possibilidade de interação com os torcedores. Nos dois casos, tratou-se de observação disfarçada, visando à conservação da natureza espontânea e do dinamismo das interações. Em todos os casos, preservamos a identidade dos torcedores.

Tais observações foram realizadas em idas aos jogos do Náutico no período de abril a dezembro de 2013. A coleta acompanhou os últimos cinco jogos realizados no Estádio dos Aflitos, sendo um válido pela Copa do Brasil e os demais pelos campeonatos Pernambucano e Brasileiro, e os primeiros jogos realizados na Arena Pernambuco, sendo o jogo amistoso de inauguração do estádio, um jogo pela Copa Sul-americana e os demais pelo Campeonato Brasileiro, num total de dezoito. Estas observações foram registradas em notas de campos escritas e gravadas, posteriormente transcritas e transformadas em relatos observacionais.

Os resultados passam a ser apresentados a

\section{A SOMBRA DA ARENA NOS AFLITOS}

Os três primeiros jogos que acompanhamos nos Aflitos antecederam o amistoso que marcou a inauguração da Arena Pernambuco. Até este primeiro contato com a Arena, identificamos especulações e discussões, entre os torcedores, sobre o que se esperar do novo estádio. As expectativas giravam, fundamentalmente, em torno da distância, do

Interagente 1: Vai nada! Cabe 40 , não vai $20 \ldots$ a torcida do Náutico é pequena... aí vai ficar vazio. Interagente 2: Aqui vem porque aqui é próximo. Interagente 1: É..a negada sai, fica tomando uma no barzinho...

A interação revela um sentimento de desconfiança sobre a presença do torcedor no novo espaço, indicando que o Estádio dos Aflitos seja suficiente para abrigar a torcida alvirrubra que geralmente frequenta os jogos do time e que a Arena dificilmente teria grandes públicos, pois ela é grande demais para a torcida, bem como que a distância seja um empecilho, sinalizando que a torcida, em sua maior parte, mora nas proximidades dos Aflitos. Tal desconfiança é vastamente marcada pelas inflexões ora exclamativas, ora interrogativas (entoação, duração da elocução). Por outro lado, fica evidente partir do ponto de vista do que capturamos em cada estádio, mas sempre tendo o outro estádio como referência, uma vez que nos ficou claro, no momento da realização da pesquisa, esta mútua relação. Sendo assim, iniciamos pelas observações nos Aflitos e seguimos pelas da Arena, estas divididas em dois momentos: quando era estranhada e, depois, quando começou a ser reconhecida. Cada seção é apresentada em texto corrido, intercalado de relato e interações. As inferências são sempre sustentadas com menção às categorias do protocolo de análise. A teoria aparece pontuada nessas inferências, ainda que sem se fazer menção direta a ela - o que ocorre na seção final - em prol do estilo e da dinâmica adotada no texto. Esta opção se deu pela noção de que a etnografia deve ser narrada como uma descrição densa (Geertz, 1989) sobre a comunidade investigada - o que não tem a ver, necessariamente, com o tamanho do texto, mas com o debruçar-se sobre as peculiaridades observadas, ainda que, evidentemente, uma maior densidade textual teria sido usada se não fossem as limitações de espaço para a elaboração do artigo. Apesar disto, apresentamos os aspectos observados dentro de uma organização: em cada seção identificamos aspectos mais gerais (destacados em negrito) evidenciados por situações particulares (destacados em sublinhado).

tamanho e das características da Arena.

Para alguns torcedores a Arena se apresentava como demasiadamente grande e distante para a torcida do Náutico. Em uma interação registrada no dia da partida contra o Crac, pela Copa do Brasil, uma preocupação evidente era a presença da torcida nos jogos do novo estádio:

Interagente 2: Aí vai pegar o carro para ir para Arena?

Interagente 1: Jogo no meio da semana, 10 horas da noite, em São Lourenço?

que a proximidade destacada não diz respeito apenas à distância física da Arena, mas ao fato de os arredores dos Aflitos representar um espaço já íntimo e familiar aos torcedores, onde a "negada" pode tomar "uma" (alternância de código, conhecimento de mundo).

Identificamos também que a questão da distância está associada à necessidade de deslocamento para se ir à Arena. No dia da partida contra o Santa Cruz, pelo Campeonato Pernambucano, alguns torcedores conversavam e especulavam sobre isto. 
Interagente 1: Eu tenho medo, eu tenho muito medo, por que a torcida do náutico não vem para jogo...

Interagente 2: Não vem não... O pessoal vem, mas lá em São Lourenço?

Interagente 1: Mas agora tem um atrativo.

Interagente 3: Tem... a primeira grande vitória é um atrativo; a segunda pode, mas na terceira não vai mais não.

Interagente 1: Mas lá você tem conforto, rapaz...

A desconfiança da torcida está aqui relacionada à dificuldade de ir para a Arena. Podemos observar isto no questionamento inicial dos torcedores (entoação, duração da elocução), apesar da presença de atrativos fazerem a torcida se locomover para a Arena, como acena um dos torcedores, ao relatar a questão do conforto do novo espaço (conhecimento de mundo). No entanto, um ponto importante foi levantado: não faz parte da cultura da torcida fazer uso do metrô, meio de transporte que será bastante usado na ida à Arena; leva-se em consideração o hábito do torcedor das proximidades dos Aflitos, que vai caminhando para o estádio; não se levou em conta que, para outros torcedores, ir para os Aflitos também requer o uso de transporte público

Interagente 1: Pro senhor vai ser uma beleza, né? Interagente 2: Rapaz... e eu vou caminhando ou

Demonstrando se importar com o que a mudança representa para ele, que poderá ver o "show" mais próximo de onde mora, o torcedor destaca (tom, entoação, expressão facial) a possibilidade de poder ir andando ou de bicicleta para a Arena, em uma situação diferente daqueles que moram perto dos Aflitos (contexto, conhecimento de mundo).

Interagente 1: Ver o jogo sentado... tem uma estrutura da porra: estacionamento, a facilidade... Interagente 2: Shopping para deixar a mulher!

Essas expectativas desenham um espaço que ainda é desconhecido, na qual não existem laços entre a torcida e o espaço e indica que muitos iriam para a Arena, pelo menos num primeiro momento, movidos pela curiosidade da descoberta do novo espaço. $\mathrm{Na}$ interação apresentada, os torcedores listam, com euforia (tom, entoação, conhecimento de mundo, tom, variações ortoépicas), os serviços que esperam encontrar na Arena, que assumem que serão diferentes daqueles encontrados nos Aflitos.

Mesmo depois do amistoso inaugural da Arena Pernambuco, os dois primeiros jogos do Náutico pelo Campeonato Brasileiro estavam agendados para ocorrerem nos Aflitos, o que foi uma oportunidade para capturarmos, ainda sob a presença do velho estádio, as primeiras impressões sobre o novo espaço.

Uma dessas impressões confirmou uma das expectativas que havia. Para muitos torcedores, $\underline{\mathbf{0}}$ lá você tem loja..

Interagente 3: Tem conforto, mas quero ver chegar lá... tem que chegar lá... não é aqui na Av. Norte não... é longe pra caralho! Em dia de jogo, metrô vira lotação... Quem vai com a família, com a mulher, com filho não é para metrô não... ou vai pagar para ir de carro, ou vai de taxi... Aqui não tem a cultura de metrô não... Eu tenho medo disso aí, eu tenho medo disso...

e, para alguns desses, o uso metrô faz parte de seu cotidiano (conhecimento de mundo).

A potencial dificuldade de deslocamento para a Arena vislumbra o que talvez seja o que se entende como torcida típica do time, que de padrão socioeconômico elevado e que reside sobremaneira nos bairros circunvizinhos ao Estádio dos Aflitos. Entretanto, uma visão oposta pode ser identificada à parte da torcida que não se enquadra neste perfil; uma oportunidade para a parcela da torcida com perfil socioeconômico mais modesto e que mora em subúrbios que se localizam mais próximos da Arena do que dos Aflitos. Em uma interação, também no dia do jogo contra o Crac, este aspecto pode ser evidenciado.

de bicicleta... coisa linda... o show vai ser lá agora! - Disse, dando uma gargalhada.

Para alguns torcedores, no entanto, é justamente os serviços e as instalações propiciados pelo novo espaço o que poderia contribuir para a presença da torcida na Arena. No dia da partida contra o Ipiranga, pelo Campeonato Pernambucano, um grupo de torcedores especulava sobre esse aspecto:

Interagente 1: Lanchonete à vontade, restaurante... Interagente 3: Até pela curiosidade, saber como é, vai dar [gente] nesse jogo de estreia.

deslocamento foi o principal problema encontrado na inauguração, pois, naquela primeira ida à Arena, muitos enfrentaram problemas com o fechamento das estações de metrô após a meia-noite, fazendo com que muitos torcedores procurassem outros meios de locomoção para voltar para casa. Em situação em que alguns torcedores falavam sobre a experiência do primeiro jogo, um torcedor relatou sua experiência: "eu lembro que no amistoso, Náutico e Sporting, eu fui... bicho, eu desci ali na Santa Luzia [estação de metrô da Região Metropolitana do Recife], não tinha taxi, não tinha nada, pô... caralho, ninguém na rua! Mermão... essa Arena vai foder a galera, pô, na moral...". Observando a forma como descreveu o momento (entoação, tom) em seu relato, a insatisfação e a preocupação do torcedor fica evidente.

A segunda impressão particular girou em 
torno de críticas aos serviços oferecidos. Conforme descrevemos anteriormente, havia uma expectativa no ar acerca dos serviços e atrativos que seriam (ou poderiam ser) encontrados na Arena, diferentes daqueles oferecidos nos Aflitos (e nos outros estádios locais, frequentados pela torcida alvirrubra). O preço e a qualidade dos serviços prestados foram os principais pontos que observamos nas reações dos torcedores. Muitos, por exemplo, estranharam a marca do refrigerante disponível — até então ainda era uma marca desconhecida - e os preços cobrados pelos lanches. Outro ponto que pode ilustrar esta questão diz respeito ao modo como os assentos para a primeira partida foram vendidos: muitos torcedores compraram ingressos para o setor leste, mas quando chegaram à Arena esses assentos não estavam disponíveis, pois muitos torcedores de outros setores, e que chegaram mais cedo na Arena, aparentemente ocuparam tais assentos, gerando discussões entre torcedores e funcionários da Arena até o início da partida.

O primeiro contato com a Arena também provocou a inquietação da torcida quanto ao modo como a Arena seria utilizada: muitos questionavam em qual setor ficariam os sócios e as torcidas organizadas, uma vez que, nos Aflitos, a torcida já se acostumara com a disposição dos espaços e com o consequente modo de ocupação pelos torcedores. É válido observar que, independente da forma como os torcedores (do time alvirrubro ou dos visitantes) fossem posicionados na Arena, a arquitetura do local

Interagente 1: Tô a fim de me associar... neste lance de trinta real...

Interagente 2: Eu já sou sócio, mas fui lá tirar uma dúvida para ver como é. A menina respondeu: "o senhor paga essa mensalidade; mês que vem vai ser trinta reais". Eu: "peraí: a pessoa

Observamos nesta interação não só há dúvidas acerca de mudanças da relação entre clube e torcida, com a chegada da Arena, como também uma aparente demarcação que torcedores fazem entre sócios e não-sócios. Ao relatar a conversa com uma funcionária do clube (entoação), o interagente 2 ficou irritado (tom) ao ver que o novo programa ainda não estava bem esclarecido quanto ao que é oferecido como vantagens para os sócios, e ao saber que novos sócios terão o mesmo direito que tem; para ele, ser sócio antigo lhe dá direitos que não podem ser o mesmo para os torcedores que estão se associando ao clube, movidos pela atual campanha.

Outra impressão deixada pela primeira ida à Arena foi a de que ali iria existir novos procedimentos e regras de convívio. Também no jogo contra o Vitória, imediatamente posterior ao amistoso na Arena, um torcedor discutia com um funcionário do clube na divisa entre a Arquibancada Lateral e a Central. Ele queria entrar sem o ingresso, somente fazendo uso de sua carteira de sócio. O torcedor não foi adaptada para a realidade do futebol local (e, seguramente, podemos dizer da realidade do futebol brasileiro): como a Arena foi construída dentro dos padrões da FIFA para estádios da Copa do Mundo, os setores de um mesmo nível (anel superior da Arena, por exemplo) não são separados, pois, como a venda dos ingressos nestes estádios levam em consideração a numeração dos assentos, a setorização é desnecessária. No entanto, a Arena teve seus espaços separados por estruturas improvisadas (grades portáteis), impedindo que o indivíduo que comprasse um ingresso do setor sul fosse para o setor leste, por exemplo. Este, por sinal, foi um dos pontos que a torcida mais reclamou no primeiro jogo realizado pelo Náutico na Arena, conforme ilustramos anteriormente. No segundo jogo ali realizado (contra a Ponte Preta), observamos que não havia ainda os bloqueios separando setores de uma mesma torcida - havia somente a separação do setor destinado para a torcida visitante.

Outro ponto identificado disse respeito a dúvidas sobre os benefícios que teriam o sócio torcedor na Arena. Como nos Aflitos os sócios do clube tinham preços específicos e outros benefícios, como fila exclusiva para a compra de ingressos no estádio, a ida para Arena trouxe o questionamento acerca do que seria oferecido aos sócios. Dias antes do jogo contra o Vitória, fora anunciado um novo plano para sócios; no entanto, o interesse maior da torcida foi saber quais os benefícios que seriam oferecidos para os sócios na Arena.

que tá se associando agora vai ter o mesmo direito que eu, pagando mais barato. Qual minha vantagem?". E ela... [o torcedor faz uma cara de quem não sabe de nada, reproduzindo assim a resposta da funcionária]. Qual o desconto que vai ter na Arena? Ela não sabe não...

conseguiu e, no final da discussão, falou direcionado não somente ao funcionário, mas para aqueles que estavam próximos e que viram a discussão: "não... nada não... tá achando que aqui é a Arena?".

No episódio, o indivíduo não aceitou a nova regra de acesso ao espaço que ele queria ir; o que vale, para ele, é o que fora praticado antes e o que o status que ele detém (o de sócio do clube) permite fazer. Ao ter o pedido negado, o torcedor insinua (entoação, tom), de forma que não só o funcionário ouvisse, mas também os torcedores ali próximo (altura de voz), que ali está ocorrendo uma rigidez de regras, um processo rigoroso que antes não se tinha, mas que agora tem; regras vivenciadas na Arena. Com o comentário, o torcedor ressalta que o Estádio dos Aflitos tem suas próprias regras de convívio, frente a regras externas. 


\section{A SOMBRA DOS AFLITOS NA ARENA}

Na relação entre torcida e o novo espaço, o primeiro contato com as instalações físicas oferecidas já nos revelam impressões significativas por parte da torcida acerca da Arena. A primeira impressão identificada foi a constatação de que a Arena é um espaço moderno, típica daqueles que visitavam o espaço pela primeira vez. No dia da partida entre Náutico e Criciúma, um casal conversava no Setor Sul da Arena. O homem jogava conversa fora, enquanto sua companheira mais escutava do que falava, visto que mal ouvimos a voz dela. Em um determinado momento, o homem comentou: "cadeirinha boa essa, né? É melhor do que tá com o cu aqui, ó..." - temos uma alternância de código quando o torcedor usa uma palavra diferente do padrão usado em sua fala; e, com o modo e a expressão usada ("ó"), entendemos que ele fazia menção ao chão de concreto (movimento dêitico). Logo em seguida, completou: "Na Ilha, no Arruda é tudo assim, ó" - repetindo o modo de indicação "piso quente, o sol bate... oxi...". Na interação, o homem evidencia (entoação) o conforto que é estar sentado nas cadeiras das arquibancadas da Arena, evocando outros estádios e apontando a diferença (tom, variações ortoépicas), mostrando que a Arena é melhor do que aqueles. No entanto, ele cita os estádios dos seus principais rivais, e não os Aflitos que, também, segue a mesma estrutura oferecida pelos outros estádios citados. Podemos deduzir que ou ele isentou o antigo estádio da crítica, ou os Aflitos é coisa do passado.

A Arena tem usado uma divisão de setores que variou ao longo da temporada de jogos. Em algumas situações, foi possível ver a torcida observando os diferentes espaços do estádio, no que diz respeito ao acesso, visão de campo, acomodações e serviços. Neste contexto, outra impressão da torcida foi diferenciar os espaços da Arena. Apesar da divisão do Estádio dos Aflitos, muitos espaços eram compartilhados entre os frequentadores; por outro lado, como já era esperado pela torcida, a proposta da Arena era oferecer espaços diferenciados, que puderam ser experimentados aos poucos, e por alguns torcedores. No mês de agosto, algumas pessoas participaram de um experimento, cujo objetivo foi testar um cartão magnético. Como prêmio, foram distribuídos ingressos para o Setor Oeste para a partida do Náutico contra o Atlético Mineiro. No dia do jogo, esses torcedores aproveitaram para conhecer o ambiente climatizado, que tinha música ao vivo, sofás, mesinhas e outros assentos. Ao final do jogo, alguns torcedores foram para o banheiro antes de sair da Arena. Lá, um grupo de torcedores já estava saindo do local, quando um deles comentou: "ó...o banheiro é diferente, né? Aqui as cabines são separadas, e lá a gente mija no muro! "A situação possibilitou a constatação (entoação, movimento dêitico), por parte do torcedor, de que ali se tratava de um espaço distinto dentro da Arena, fazendo referência aos banheiros dos outros setores (conhecimento de mundo), onde não se tem mictórios individuais; tem-se somente no chão vários ralos, com divisórias delimitando os espaços reservados para os indivíduos.

Entretanto, a torcida também se deparou com situações desfavoráveis, que suscitaram reações. Alguns torcedores entenderam que o modo de ocupação da Arena era injusto. Se, por um lado, a separação dos setores e a ocupação dos Aflitos (como o espaço para a torcida visitante, sócios e para aqueles que compravam ingressos através do programa Todos com a Nota) eram bem definidos, as arrumações propostas pela Arena provocaram situações nas quais torcedores achavam que o espaço que ocupavam não era apropriado para eles, e que os que ocupavam espaços considerados melhores não mereciam estar ali. Ilustramos a situação com uma interação observada no dia da partida contra o Internacional - uma das primeiras partidas realizadas nas tardes de domingo. Nesse dia, a maioria das pessoas que chegaram cedo permaneceu na área das lanchonetes, pois a luz do sol ainda estava presente e batia, principalmente, na região leste do anel inferior da Arena, local onde fica, predominantemente, a torcida do Náutico. Com o tempo, os torcedores começaram a procurar o melhor lugar nas arquibancadas. Um grupo de torcedores estava conversando sobre o time e outros temas, quando de repente tem início uma conversa sobre os espaços da Arena. Sentados no Setor Leste, o grupo passou a observar o Setor oposto, buscando entender a forma como ele é ocupado. Em um dado momento, um torcedor revela a vontade de ver o jogo no Anel Superior daquele setor:

Interagente 1: Agora posso dizer, ô moço... vou ver se vou lá pra cima. [referindo-se ao setor oeste do anel superior] Pode ser o que for aquela porra lá...

Interagente 2: Ali é Todos com a Nota

Interagente 1: É não! Todos com a Nota é aqui [apontando para a parte de cima do setor leste], começando dali do bloco F...

Interagente 2: Só a parte de cima. Mas tanto faz ser lá como aqui.

Interagente 1: Mas ali não leva sol, [fulano]!

Interagente 2: Aqui em cima não bate não... olha lá.

Interagente 1: Estão melhor do que aqui...

Interagente 3 : Todos com a nota é ali em cima?

Interagente 1: Ali em cima é todos com a nota...

Aqui é bom... parece nos Aflitos, bem pertinho, né?

Interagente 3: Ali não pega sol não, ó! Lá em cima...

Interagente 1: Lá em cima, não!

Interagente 3: Mas ali fica muito distante do campo

Interagente 1: Ali fica muito distante do campo... mas aí eu venho com meu binóculo... 
Esta interação ilustra a torcida conhecendo o novo espaço. Convicto de sua posição na discussão, o Interagente 1 criou e buscou manter sua face (tom, entoação), frente a ameaça que sofria do outro torcedor, que defendia uma informação diferente. Após mostrarem que ele estava errado (conhecimento de mundo), o Interagente 1 mudou de postura (footing). Isto fica evidente quando ele responde (agora, fazendo uso das novas informações que passou a ter) ao colega com a mesma dúvida levantada durante e discussão, mas também quando ele atribui ao local em que estava uma característica específica, levando-se em consideração o setor

Interagente 1: Agora... - faz uma pequena pausa antes de completar - o jogo das nove e quarenta e cinco é mal..

Interagente 2: Pois é - respondeu, de forma mais alongada do que a pronúncia normal. Interagente 1: Nesse horário eu não venho não.

Este diálogo entre torcedores mostra a dificuldade de ir para o novo local de jogos do time (conhecimento de mundo, entoação, tom). A situação é vista como uma dificuldade em relação aos Aflitos.

Outro tipo de reação foi o estranhamento da torcida com as normas de conduta no novo espaço, uma vez que nos Aflitos não havia regras semelhantes. Dos procedimentos para comprar lanches ao modo de sentar-se nas arquibancadas, a torcida passou a conviver com regras e fiscalização, por parte dos orientadores e dos seguranças da Arena. Comportamentos antes considerados normais e

Eu vou ficar na cadeira mesmo assim e quero ver ele reclamar... porra...é foda! Brincadeira, porra! Oa... existe tu tá na tua casa, botar o pé na cadeira e a

A orientação dada pelo funcionário da Arena para o torcedor soa comum, tendo em vista que ali é um espaço que tem regras a serem seguidas por aqueles que frequentam o espaço, da mesma forma que uma pessoa não pode fumar em lugar fechado ou colocar os pés nas cadeiras de um cinema, por exemplo. Para este torcedor, no entanto, esta regra é inadequada, como fica claro em sua reação e em seu desabafo (tom, entoação): para ele, se ali é a casa de seu time, ele pode se comportar da forma como se comportaria em casa.

Associado a esses inconvenientes, com o cenário desenhado naquele ano - o clube realizou uma má campanha no Campeonato Brasileiro, que resultou em seu rebaixamento no ano em que passou a mandar seus jogos na Arena - , um confronto mais direto foi estabelecido entre a Arena e os Aflitos. Alguns torcedores acreditaram que as derrotas estavam ligadas ao fato de que o time está jogando fora dos Aflitos, como se lá tivesse algo que na Arena não tem, sem mostrar claramente argumentos que destinado ao Todos com a Nota (antes, ele colocara que, pelo fato que aquele local sofre com a presença do sol, o setor do Todos com a Nota era melhor).

Embora não sejam uma novidade os jogos realizados à noite, outra reação da torcida está ligada à volta para casa após os jogos da noite. A repercussão do caminho da volta no dia do primeiro jogo, como dos demais realizados à noite, provocou preocupação e reclamações acerca da condição. No trajeto feito de ônibus que leva os torcedores para a Arena, dois torcedores conversavam durante a viagem.

Interagente 2: [Fazendo um gesto com a mão, como se tangesse algo no ar] Se depender de mim, não vai ter ninguém no estádio.

Interagente 1: Oxi... se depender de mim vão jogar sozinho

banais passaram a ser restringidos, como também práticas simples e informais passaram a ter etapas intermediárias e formais. Um exemplo desse tipo de estranhamento ocorreu no dia da partida contra o São Paulo: enquanto aguardava o início da partida, um torcedor usava o celular. Um dos orientadores da Arena, como de praxe, solicitou ao torcedor que retirasse o pé da cadeira da frente. O torcedor retirou, mas ficou irritado (tom, altura de voz) e, imediatamente, comentou (entoação) com quem falava pelo celular:

turma mandar tu tirar? Complicado, né? Entendesse? Complicado, pô... o cara na casa do cara e não pode botar o pé no sofá do cara! Porra, brincadeira, cara...

justificassem tal constatação. No entanto, é possível inferir que, para os torcedores, não existe ali a participação maior da torcida - a "pressão" de uma torcida mais próxima ao campo de jogo —, assim como o "fator campo" (por "conhecer" as características do campo, o time tem ao seu favor essa familiaridade). Tal reação pôde ser vista já no primeiro jogo oficial do Náutico, quando o time foi derrotado pela Ponte Preta. Naquele jogo, após o time levar o segundo gol, a torcida começou a demonstrar sua insatisfação, a gritar e a xingar os jogadores em campo. Neste momento, um torcedor comentou, como se ali desse um conselho, de modo que não somente as pessoas que estavam ao lado, mas também um pouco mais afastadas pudessem ouvir (entoação, tom): "é melhor a gente voltar para os Aflitos".

O clima de estranhamento esteve presente também no entendimento de que a torcida não se comportava na Arena com o mesmo entusiasmo que tinha nos

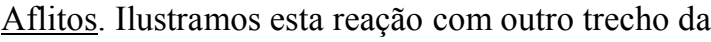


interação observada no dia da manifestação da torcida na sede do clube, no mês de maio, quando

Interagente 1: Pô, bicho... a torcida ali, velho... foi, aquele jogo foi estranho... esse último agora [o torcedor fez referência ao jogo contra a Ponte Preta] foi estranho, foi horrível. Eu olhava assim

O conteúdo e a forma (tom) como o primeiro torcedor descreveu o ambiente (conhecimento de mundo) e a constatação do segundo (entoação) evidenciam a ideia de que a animação da torcida

\section{O RECONHECIMENTO DO NOVO E O ESTRANHAMENTO DO VELHO}

Com o tempo, entretanto, identificamos um processo de acomodação da torcida à arena. Evidentemente, não foi um processo que não tenha passado por uma transição. Por outro lado, identificamos certa nostalgia que apontava para o argumento de que os Aflitos têm coisas que ainda o

Interagente 1: Sabe em que aqui é melhor que os Aflitos?

Interagente 2: Em tudo.

Interagente 1: Nos Aflitos, a arquibancada aqui era mais baixa. Aqui fica mais alto, por isso dá a

Quando o primeiro torcedor faz a pergunta (entoação) e o segundo responde "em tudo", este adotou uma posição frente à comparação entre Aflitos e Arena; neste primeiro momento, como sua resposta indicou, o torcedor assume que, para ele, a Arena é melhor em tudo, se comparado aos Aflitos (entoação, tom). O primeiro torcedor, apesar não assumir a mesma postura radical do segundo (tom), assumiu que a Arena é melhor do que os Aflitos, pelo menos no quesito que ele expressou. Ao ouvir o argumento do amigo, no entanto, o segundo torcedor nos apresenta um fator ligado aos Aflitos que, para ele, parece ser mais importante do que as possíveis vantagens da Arena (conhecimento de mundo). Ele mudou, então, sua postura (footing), e assim provocou também a mudança da face do amigo, que

Interagente 1: não tinha mais condições de tá ali: não pode crescer... um estádio velho, acabado, não tem um banheiro decente... você não pode

levar sua esposa, não pode levar uma pessoa, não tem uma acomodação adequada pra você... Tinha que criar, de pensar lá na frente. E outra: $\mathrm{O}$ sócio. O que é que o sócio tinha no Náutico, pelo o amor de Deus? Não tinha. Não oferece nada... mas aqui, aqui, também não tá oferecendo, tudo bem, mas pelo menos... tirando esse sol quente na cara.

A opinião do torcedor mostra (entoação, tom, conhecimento de mundo) que, apesar de não ilustrar com características positivas concretas oriundas da mudança (ele destaca, por exemplo, que falavam sobre a Arena:

a torcida, sei lá... eu ouvia o goleiro falando, velho... caralho, era estranho, velho...

Interagente 1: A morgação da Arena.

típica da época dos Aflitos não estava presente na Arena. Observamos que na Arena as pessoas ficam mais espalhadas, não construindo o que os torcedores chamavam de "caldeirão".

faz ser melhor que a Arena, quando a torcida enaltece fatores ou características dos Aflitos que não estão presentes no novo estádio. No dia do jogo entre Náutico e Vasco da Gama, durante uma conversa entre um grupo de torcedores, um dos torcedores perguntou para o grupo:

impressão de tá mais próximo.

Interagente 2: Pelo menos lá a gente ganhava.

Interagente 1: É...o bom dos Aflitos era que a gente ganhava.

acabou concordando com o argumento a favor dos Aflitos.

Por outro lado, a inferioridade dos Aflitos em certos aspectos foi sendo exposta e ilustrou gradualmente $\mathrm{o}$ início de um processo de estranhamento por parte dos torcedores. Identificamos, neste cenário, a declaração de que o Estádio dos Aflitos não oferecia mais benefícios para a torcida. Os argumentos usados atestavam racionalmente as desvantagens do antigo espaço, como também expressavam com certa aspereza sua inferioridade, comparada à Arena. Durante a partida entre Náutico e Cruzeiro, um pequeno grupo de torcedores conversava quando, em um dado instante, um torcedor deu sua opinião sobre a saída dos Aflitos:

Interagente 2: é verdade

Interagente 1: mas nos aflitos a gente ia ter o quê? Um alambrado na cara da gente... ninguém via nada. Eu acho que tem que evoluir mesmo... tem que agora preparar o centro de treinamento cada vez mais, para formar gente. Quem sabe, se mais na frente, não arrenda esse negócio aqui? Se a arena do Sport sair mesmo, acho que isso vai ficar sendo do Náutico mesmo.

ainda não tem vantagens para os sócios na Arena), a ida para a Arena é um passo importante para o clube: ele faz isso apontando os pontos negativos em torno dos Aflitos (como a falta de estrutura), argumentando 
que o clube precisa "pensar lá na frente".

Com isso, até a associação entre a campanha do time e a Arena foi desfeita por alguns torcedores. E, de certa forma, o fim de tal associação contribui para desfazer a ideia de que time estaria vencendo, caso estivesse jogando nos Aflitos. Isto ocorreu à medida que o rebaixamento do time para a segunda

Interagente 1: Porra... porque os outros vêm e ganham?

Interagente 2: Tem que se acostumar.

Interagente 1: Tem que acostumar não!

Esta interação demonstra que alguns torcedores passaram a analisar a campanha do time mais friamente. Ao alegar que os outros times conseguem ganhar, o primeiro torcedor argumenta (tom, entoação) — a ponto de fazer com que o segundo mude de opinião (footing) — que a adaptação ao gramado da Arena não é a razão para a campanha ruim do time; afinal, se a Arena é um espaço estranho, ela assim é para todos.

Identificamos também demonstrações de um

Interagente 1: Vocês tão indo para a Arena?

Interagente 2: Eu venho todos os jogos.

Interagente 1: O meu [ingresso] foi a 60 , o

Premium [segurando o ingresso].

Interagente 3: Premium? Pô... deve ser num lugar fuderoso! Deve ser no meio...

Interagente 1: Fica no meio do... [neste momento, foi interrompido por aquele com quem conversava no momento, que se

aproximou, segurou um lado do ingresso

Apesar da variação do tamanho do público presente, a presença de novos expectadores na Arena foi constante. No caso deste jogo, tendo em vista seu contexto, observamos que a presença de novos expectadores foi maior. Presenciamos, então, o contato entre aqueles já conhecem a Arena e outros que estão indo pela primeira vez. Quando um torcedor (que, provavelmente, estava indo pela primeira vez para o campo) perguntou para os demais se estavam indo para Arena (entoação), um deles já se identificou como um torcedor "assíduo"; mostrou já ter uma relação com o espaço, enquanto que outros torcedores explicaram para o dono do ingresso sua localização na Arena (conhecimento de mundo). A conversa sobre a área Premium mostrou que, para muitos torcedores, o espaço (e, principalmente, como ele está dividido) ainda é uma novidade, mesmo para aqueles que já tinham ido para a Arena.

Com a crescente aproximação da torcida com o espaço, identificamos que, para alguns torcedores, a Arena tem regras que precisam ser respeitadas. Trazemos uma situação envolvendo o mesmo casal do dia do jogo contra o Criciúma: ao presenciar a ação de um orientador da Arena que pedia para um torcedor tirar o pé da cadeira da frente, divisão tornou-se inevitável, o que pode ser ilustrado em interação observada no dia da partida contra o Criciúma: alguns torcedores conversavam sobre o time e outros assuntos, quando surgiu como tema a notícia de que alguns jogadores alvirrubros teriam alegado que não estariam adaptados ao gramado da Arena. Ao ouvir a história, um torcedor comentou:

Interagente 2: Devia botar todo mundo pra fora! Interagente 1: É! Por que dizer que não tá adaptado a um gramado desse... e porque os outros times vêm e ganham? Né isso?

movimento no qual a torcida já estaria se familiarizando com os espaços da Arena. No último dia de jogo válido pelo Campeonato Brasileiro, em uma fila na Integração do TIP, torcedores conversavam. Enquanto três torcedores trocavam palavras sobre assuntos variados, outro torcedor (que estava um pouco atrás do trio na fila) puxou uma conversa sobre os ingressos vendidos na Arena. No meio do assunto, ele perguntou:

com uma mão e, com a outra, apontou no mapa da Arena o local que falavam, e o dono, que não soltou o ingresso, olhou para a onde era apontado]

Interagente 3: É aqui, ó... deve ser aqui na metade.

Interagente 4: É na divisa do campo.

Interagente 3: É... na divisa do campo. E é de ar condicionado, visse?

o torcedor comentou com sua companheira: "a turma sabe que... é proibido botar o pé..." e, após uma pequena pausa, fala novamente: "o pessoal pensa que aqui...", ficou reticente por um instante (duração da elocução), mas completou: “aqui não pode botar o pé na cadeira não. Se uma cadeira dessa aqui, ó, se quebrar, quem paga é a torcida do Náutico. Do Náutico Futebol Clube" (variações ortoépicas). O torcedor da interação recriminou a postura do torcedor (tom), uma vez que ele acredita que todos devem respeitar as regras do local.

Se por um lado a torcida alvirrubra passou a conviver com novos hábitos ligados ao funcionamento da Arena, a ocupação deste espaço ao longo dos primeiros meses de uso nos mostrou a ocorrência de velhos hábitos da torcida, assim como de práticas que ilustram o modo típico do cotidiano de como viver o futebol. Uma situação significativa que ilustra a presença de antigos hábitos foi a circulação de ambulantes nos arredores da Arena. O que começou com poucos vendedores que ficavam próximos ao ponto de ônibus, com suas caixas térmicas —, teve, como ponto máximo, a ocupação de um pequeno terreno descampado (já dentro dos limites da Arena) localizado às margens da 
BR-408, quando alguns ambulantes, munidos com uma estrutura maior (com carros e minivans adaptados), vendiam ali uma diversidade de produtos, como cachorro-quente, espetinhos, refrigerantes $\mathrm{e}$ cervejas. Os torcedores aproveitavam a oportunidade para fazer um lanche e tomar uma cerveja, driblando, assim, a falta de opção e os preços praticados nas dependências da Arena (onde a cerveja vendida é sem álcool). No dia da partida entre Náutico e Fluminense, no fluxo contrário da maioria dos torcedores, uma dupla seguiu subindo a área de acesso dos pedestres, indo em direção ao local onde se encontrava os ambulantes. No meio do caminho, um deles falou, em voz alta e não necessariamente voltado para o colega do lado: "o cara tem que subir isso tudinho por causa de uma Skol!". O comentário do torcedor (entoação, tom) ilustra não só sua insatisfação com o que é oferecido pela Arena, como também recuperou um hábito antigo que praticara nos arredores dos Aflitos. A presença desta pequena estrutura de serviços dos ambulantes foi combatida durante as poucas semanas que ficou instalada na região. A solução tomada pela Arena foi cercar o local invadido, impedindo novas utilizações daquele espaço.

Outra situação esteve ligada a um antigo hábito ligado ao futebol: a tentativa dos pais em transmitir para os filhos sua paixão pelo time por meio da ida ao campo. Tal prática proporciona até

\section{CONSIDERAÇÕES FINAIS: UMA MUDANÇA EM ANDAMENTO}

No decorrer de nossa pesquisa, a torcida do Clube Náutico Capibaribe significou os Aflitos e a Arena num processo dinâmico, no qual os dois espaços envolvidos possuíam sentidos que sofreram modificações. Neste processo, os dois espaços ganharam novos significados a partir de dois pontos de vista: um ligado a uma visão de mundo específica de uma sociedade, cujos valores ali praticados são frutos das relações ou laços existentes entre seus membros, e construídos ao longo de sua história; e o outro fundamentado nas regras e valores de uma ordem social universal e vigente. Estas fontes, no entanto, não estão em uma relação dialética; assim, a torcida tinha em suas mãos - e fez uso — das duas esferas de sentido, de modo que fazer uso de uma não eliminaria a possibilidade de uso da outra. Assim, evidenciamos que, para além da mudança em si, envolvendo os Aflitos e a Arena, ocorreram mudanças que envolvem a torcida e sua relação com os dois espaços.

Nas expectativas que nos mostraram como a torcida esperava a mudança e, nos argumentos usados por ela, podemos identificar indícios de uma dinâmica envolvendo esferas de valores em situações específicas. O ponto de vista da Casa ficou evidente naquelas situações nas quais a torcida enalteceu as qualidades dos Aflitos, um espaço no qual a torcida hoje a produção, a cada geração, de novos torcedores; e, como o Náutico é um dos times mais tradicionais do país, e tem, na sua história, um laço importante com um dos bairros mais antigos e tradicionais do Recife, tal prática pode ser bastante comum. No dia do jogo contra o Criciúma, observamos um torcedor acompanhado por dois filhos. Enquanto esperavam o ônibus no terminal de integração, conversavam com algumas pessoas que voltavam da Arena, no que um dos pesquisadores se integrou ao diálogo. No meio de uma conversa, o pai falou: "Mas fazer duas pessoas gostar do time, é difícil né?”. Perguntado se ele já tinha levado os filhos para os Aflitos, o homem respondeu que sim e, depois de uma pequena pausa (duração de elocução), comentou, com um ar saudoso (entoação, tom): "Mas ali, mesmo, ali era a casa da gente mesmo... ali era arretado. Ali era pressão, era cassete mesmo". Nesta situação, o torcedor sugere não existir a "pressão" da torcida na Arena; estava levando seus filhos para o novo espaço, no qual o Náutico passou a mandar seus jogos. Entretanto, o plano não estava dando certo, pois a campanha do time não estava ajudando. $\mathrm{Na}$ ocasião, o torcedor lembrou-se dos tempos dos Aflitos, invocando a postura da torcida. Este exemplo ilustrou não somente a nostalgia do torcedor, ao lembrar os Aflitos; ao levar os seus filhos para a Arena, o torcedor busca criar entre o espaço e seus filhos um laço que ainda não existe.

fica mais à vontade. Por outro lado, este olhar esteve presente em impressões e reações da torcida que se demonstravam contrárias à ida para a Arena; uma esfera de significação que representa valores contrários à mudança.

Impressões e reações retrataram o estranhamento dos torcedores com o novo espaço. Esta sensação de estranheza do torcedor evidencia a forma como estes são vistos frente às novas situações trazidas pela Arena. A presença de normas de conduta proporcionou um dos mais significativos campos de conflito entre as esferas da Casa e da Rua. Tal conflito esteve presente no modo como a divisão do espaço foi tratada: na Arena, a divisão não é fixa; ela poderá variar de acordo com as circunstâncias de cada jogo; o fator econômico condicionará frequentemente o uso do espaço. A imposição de serviços e produtos oferecidos - e que foram criticados pela torcida - são reflexos de uma nova situação trazida pela Arena, pois são produtos de acordos econômicos. Estas imposições, assim como a situação provocada pela questão da mobilidade, na qual a torcida se viu obrigada a sair do seu então status quo, ferem o estado de supercidadão que o olhar da Casa dá ao torcedor; temos assim, frente às novas práticas ligadas à Arena, os torcedores na posição de subcidadãos, estado imposto pela Rua. Por outro lado, a postura de supercidadão (e, 
consequentemente, do olhar da Casa) pôde ser vista em momentos nos quais a torcida questionava a divisão e a organização da Arena. Este olhar esteve presente também naquelas situações em que os torcedores atribuíam à mudança para a Arena a campanha ruim do clube no Campeonato Brasileiro; para a torcida, com a saída dos Aflitos (a casa do clube), o time perdeu algo que a Arena não tem.

Ao longo de nosso período de coleta, pudemos observar a transformação da Arena em um espaço reconhecido pela torcida. Os indícios deste início de reconhecimento puderam ser vistos à medida que a torcida foi se adaptando às regras do espaço e se familiarizando com as divisões da Arena. Este reconhecimento por parte da torcida foi acompanhado por uma gradual mudança do ponto de vista que a torcida usava para ver a Arena: a esfera de significados que o torcedor usava movido pela paixão foi substituída, em algumas situações, por um olhar mais imparcial, o que permitiu ver a Arena de outra maneira, permitindo o início da construção de laços entre a torcida e a Arena. E, à medida que a torcida foi passando mais tempo na Arena teve início um processo de estranhamento dos Aflitos. Inicialmente, fatores presentes na relação entre a torcida e os Aflitos eram considerados pelos torcedores e faziam do estádio um espaço ainda significativo. Em um segundo momento, no entanto, um olhar impessoal e alinhado as exigências atuais que defendem a modernização do futebol, trouxe à tona atributos negativos dos Aflitos, antes atenuados pelo olhar pessoal do torcedor; nesta situação, a torcida passou a olhar para os Aflitos sob o ponto de vista da Rua.

Sendo assim, identificamos o ponto de vista da Rua naquelas interações nas quais os torcedores passaram a ver os Aflitos como um espaço inadequado para a torcida e para o time. Nestas interações, a torcida assumia como argumento pontos alinhados a uma nova demanda do futebol atual, visando oferecer mais do que uma partida de futebol, mas também uma experiência completa para o espectador; estes argumentos se alinham ao ponto de vista da Rua.

Não que o processo de estranhamento e reconhecimento e vice-versa, para Arena e os Aflitos, respectivamente, seja linear. Vimos que a primeira ida de torcedores para Arena aconteceu a todo momento; assim, estranhamento e reconhecimento foram identificáveis em todo o período de observação. Além disso, em dadas circunstâncias a nostalgia pelos Aflitos poderia vir à tona com mais intensidade; da mesma forma, podemos especular que um título conquistado na Arena poderia fazer do espaço um lugar especial para a torcida, da noite para o dia.

A presença de circunstâncias específicas em nosso período de observação traz uma reflexão sobre um aspecto esperado e não identificado, acerca da sensação de despedida dos Aflitos. Para o momento da despedida dos Aflitos, foi lançada uma programação com várias atividades, entre shows, torneio com times formados por sócios e o lançamento da maquete do Estádio dos Aflitos. No dia do último jogo oficial, contra a Portuguesa, uma festa foi realizada para os sócios nas dependências da sede. No entanto, por mais que houvesse um clima de saudade criado pelo clube e pelas matérias jornalísticas que tratavam da despedida durante a semana e, principalmente, no dia do último jogo, não conseguimos identificar claramente nos espaços dos Aflitos o clima de despedida por parte da torcida. O contato com novo espaço - que gerou expectativas e que alimentou, provavelmente, a ansiedade na torcida em torno da ida definitiva para a Arena - e os últimos resultados do time no campeonato podem ter ofuscado o clima de despedida.

Do ponto de vista de uma reflexão da sociologia do futebol (vide Giulianotti, 2010), o presente estudo contribui para o entendimento da dinâmica existente entre um grupo social (uma torcida de clube) e um elemento significativo dentro de uma sociedade, como é o futebol para o Brasil. Nesta dinâmica, práticas sociais moldam (e são, ao mesmo tempo, moldadas por) espaços sociais compartilhados. Outra contribuição importante foi mostrar como tal dinâmica é reflexo da dimensão econômica do futebol, assim como esta também é refletida na dimensão social do esporte.

Como limitação desta pesquisa, apontamos a ampla dimensão física dos dois loci de observação. Seja sentado em uma região das arquibancadas, ou em pé nas proximidades, o alcance da observação do pesquisador foi pequeno, se comparado à área dos espaços sociais em questão. Tínhamos o cuidado de ficar próximo de agrupamentos de pessoas, mas nem sempre o tema de nossa pesquisa estava na roda de conversas dos torcedores. É importante registrar que a observação de qualquer fenômeno é limitada pelas escolhas teóricas e metodológicas da pesquisa, o que é entendido como uma delimitação, e não uma limitação, do estudo (Creswell, 2007).

Sendo assim, a realização de qualquer pesquisa deve apontar aos investigadores possibilidades identificadas no campo, mas não consideradas no escopo do estudo, o que pode ser pensado como oportunidades para futuras pesquisas. Como desdobramentos desta pesquisa, apontamos primeiramente a possibilidade de analisar a Arena Pernambuco como "casa" de duas torcidas: tal possibilidade poderá existir se caso o Sport Club do Recife - que almeja construir sua própria arena passar a mandar suas partidas na Arena, dividindo o espaço com o Náutico por cerca de quatro anos; teríamos a possibilidade de analisar, assim, o comportamento das duas torcidas rivais em uma situação na qual dividiriam o mesmo espaço. 


\section{REFERÊNCIAS}

Andrade, R. F., \& Braga, S. I. G. (2014). Futebol e torcedores em Manaus (AM): breve digressão e etnografia multissituada em 'clima' de Copa do Mundo na cidade. Ponto.Urbe, 14(1), 1-16.

Barreto, T. V., \& Nascimento, C. F. B. (2011). Os espaços físicos e o habitus dos torcedores brasileiros em estádios de futebol: o que pode mudar com a adoção do padrão FIFA para a Copa de 2014?. In: Encontro Anual da Associação Nacional de Pósgraduação e Pesquisa em Ciências Sociais, 35, Caxambu, 2011. Anais..., Anpocs.

Berger, P. T., \& Luckmann, T. (2006). A construção social da realidade. 26. ed. Petrópolis: Vozes.

Birdwhistell, R. L. (1986). A kinesic-linguistic exercise: the cigarette scene. In: J. J. Gumperz, \& D. Hymes (org.).

Directions in sociolinguistics: the ethnography of communication. New York: Basil Blackwell, 381404.

Caldas, W. (1997). Futebol e cultura brasileira. Intercom, 20(1), 69-86.

Capraro, A. M. (2015). "Diz-me como jogas e te direis quem és...": estilos de jogar futebol em Pasolini, Freyre e DaMatta. História Unisinos, 19(3), 283-292.

Capraro, A. M. (2004). O Estádio Joaquim Américo - a "Arena da Baixada" - e a identidade clubística do torcedor do Clube Atlético Paranaense. Campos, 5(1): 131-149.

Cleland, J. \& Cashmore, E. (2014). Fans, racism and british football in the twenty-first Century: the existence of a 'colour-blind' ideology. Journal of Ethnic and Migration Studies, 40(4), 638-654.

Cleland, J. \& Cashmore, E. (2016). Football fans' views of racism in British football. International Review for the Sociology of Sport, 51(1), 27-43.

Creswell, J. W. (2007). Qualitative inquiry and research design: choosing among five approaches. 2 . ed. Sage Publications: Thousand Oaks.

DaMatta, R. (2006). A bola corre mais que os homens: duas copas, treze crônicas e três ensaios sobre futebol. Rio de Janeiro: Rocco.

DaMatta, R. (1997). A casa \& a rua: espaço, cidadania, mulher e morte no Brasil. 5. ed. Rio de Janeiro: Rocco.
DaMatta, R. (1982). Futebol: ópio do povo X drama de justiça social. Novos Estudos, 1(4), 54-60.

Fernandes, D. H. (2013). A nova infraestrutura de arenas e a Copa de 2014: impulsionando a cadeia de entretenimento no Brasil. Cadernos FGV Projetos, 22(1), 62-67.

Geertz, C. (1989). A interpretação das culturas. São Paulo: LTC.

Giglio, S. S. \& Spaggiari, E. (2010). A produção das ciências humanas sobre futebol no Brasil: um panorama (1990-2009). Revista de História (USP), (163), 293-350.

Giulianotti, R. (2010). Sociologia do Futebol: Dimensões Históricas e Socioculturais do Esporte das Multidões. 2. ed. Rio de janeiro: Nova Alexandria.

Goffman, E. (1981). Footing. In E. Goffman (Ed.), Forms of talk (pp. 124-159). Philadelphia: University of Pennsylvania Press.

Goffman, E. (1967). On face-work, In E. Goffman (Ed.), Interaction ritual: essays on face-toface behavior (pp. 5-46). New York: Penguin Books.

Gumperz, J. J. (1982). Contextualization conventions. In J. J. Gumperz (Ed.), Discourse strategies (pp. 130-152). Cambridge: Cambridge University Press.

Gumperz, J. J. (1982). Conversational code switching. In J. J. Gumperz (Ed.), Discourse strategies (pp. 59-99). Cambridge: Cambridge University Press.

Gumperz, J. J. (2003). Interactional sociolinguistics: a personal perspective. In $\mathrm{D}$. Schiffrin, D. Tannen, \& H. E. Hamilton (Eds.), The handbook of discourse analysis (pp. 215-228). Malden: Blackwell Publishing.

Gumperz, J. J. (1982). Prosody in conversation. In J. J. Gumperz (Ed.), Discourse strategies (pp. 100129). Cambridge: Cambridge University Press.

Gumperz, J. J. (1982). Socio-cultural knowledge in conversational inference. In J. J. Gumperz (Ed.), Discourse strategies (pp. 153-171). Cambridge: Cambridge University Press.

Gumperz, J. J., \& Hymes D. (1986). Introduction. In J. J. Gumperz \& D. Hymes (Eds.), Directions in sociolinguistics: the ethnography of communication (pp. 1-25). New York: Basil Blackwell. 
Ianni, O. (2002). Tipos e mitos de pensamento brasileiro. Sociologias, 4(7), 176-187.

Kaz, L. \& Silva, P. (2013). Dando tratos à bola: futebol e Brasil. Revista USP, (99), 67-78.

Merkel, U. (2007). Milestones in the development of football fandom in Germany: global impacts on local contests. Soccer \& Society, 8(2/3), 221-239.

Leão, A. L. M. S. \& Mello, S. C. B. (2007). Apresentando a Etnografia da Comunicação ao Campo da Pesquisa em Administração. In I Encontro de Ensino e Pesquisa em Administração $e$ Contabilidade. Recife, PE.

Nascimento, A. S. (2014). A metrópole e as perfídias do capital: uma análise da relação entre Estado, megaeventos esportivos e grandes projetos de desenvolvimento urbano na (re)produção do capital e da cidade contemporânea. Revista Brasileira de Estudos Urbanos e Regionais, 16(2), 35-58.

Nascimento, C. F. B. \& Barreto T. V. (2013). Habitus dos torcedores brasileiros e adoção do padrão FIFA nos estádios da Copa do Mundo de futebol 2014. Estudos de Sociologia, 2(1), 1-19.

Pluri Stochos. $1^{a}$ pesquisa Pluri Stochos tamanho de torcidas. Retirado de http:/Www.pluriconsultoria.com.br/uploads/relatorios/REPORT $\% 20$ PLURI\%20STOCHOS\%20\%20TAMANHO\%20DE\%20TORCIDAS.pdf.

Saville-Troike, M. (2003). The ethnography of communication: an introduction ( $3 \mathrm{a}$ ed.). Malden: Blackwell Publishing.

Seixas, T. \& Lopes, J. P. S. R. (2012). Copa do Mundo 2014: um estudo sobre o processo de candidatura de Pernambuco. Revista Intercontinental de Gestão Desportiva, 2(1), 1-15.

Souto, L. \& Torres, R. (2010). Arenas da Copa 2014: o desafio da viabilidade dos investimentos. Cadernos FGV Projetos, 13(1), 44-52.

Stone, C. (2007). The role of football in everyday life. Soccer \& Society, 8(2/3), 169-184.

Tavoralo, S. B. F. (2008). “À sombra do mato virgem...": natureza e modernidade em uma abordagem sociológica brasileira. Ambiente $e$ Sociedade, 11(2), 273-287.

Wagner, T. (2011, Out.). Agora é oficial: Náutico vai jogar na Arena Pernambuco. Blog do torcedor. Retirado de http://blogs.ne10.uol.com.br/torcedor/2011/10/17/agora-eoficial-nautico-vai-jogar-na-arena-pernambuco. 